\section{Documents pour l'histoire des techniques}

Nouvelle série

20 | 2e semestre 2011

L'expérimentation « en plein air » ou " grandeur nature »: Une pratique scientifique au service de l'action (XIX ${ }^{\mathrm{e}}-\mathrm{XX}^{\mathrm{e}}$ siècles)

\title{
Aline Durand (dir.), Plantes exploitées, plantes cultivées, cultures, techniques et discours. Etudes offertes à Georges Comet
}

Cahier d'histoire des techniques, $n^{\circ}$ 6, Aix-en-Provence, Presses de l'Université de Provence, 2007, 178 p.

\section{Georges Carantino}

\section{(2) OpenEdition}

Journals

\section{Édition électronique}

URL : http://journals.openedition.org/dht/1835

DOI : $10.4000 /$ dht. 1835

ISSN : $1775-4194$

Éditeur :

Centre d'histoire des techniques et de l'environnement du Cnam (CDHTE-Cnam), Société des élèves du CDHTE-Cnam

\section{Édition imprimée}

Date de publication : 1 décembre 2011

ISBN : 978-2-9530779-7-1

ISSN : 0417-8726

\section{Référence électronique}

Georges Carantino, «Aline Durand (dir.), Plantes exploitées, plantes cultivées, cultures, techniques et discours. Etudes offertes à Georges Comet », Documents pour l'histoire des techniques [En ligne], 20 | 2 e semestre 2011, mis en ligne le 03 octobre 2012, consulté le 24 septembre 2020. URL : http:// journals.openedition.org/dht/1835; DOI : https://doi.org/10.4000/dht.1835

Ce document a été généré automatiquement le 24 septembre 2020.

(c) Tous droits réservés 


\section{Aline Durand (dir.), Plantes exploitées, plantes cultivées, cultures, techniques et discours. Etudes offertes à Georges Comet}

Cahier d'histoire des techniques, $n^{\circ}$ 6, Aix-en-Provence, Presses de

l'Université de Provence, 2007, 178 p.

Georges Carantino

\section{RÉFÉRENCE}

Aline Durand (dir.), Plantes exploitées, plantes cultivées, cultures, techniques et discours. Etudes offertes à Georges Comet, Cahier d'histoire des techniques, $n^{\circ}$ 6, Aix-en-Provence, Presses de l'Université de Provence, 2007, 178 p. 
1 Ce sixième numéro de Cahier d'Histoire des Techniques, présenté par Aline Durand, est dédié à Georges Comet. Il s'inscrit dans la série qu'il a fondée avec Marie-Claude Amouretti afin de rendre plus lisible l'histoire des techniques. Ce sixième Cahier est le premier de quatre volumes d'hommage à Georges Comet articulés chacun autour de thématiques qui lui sont chères. Il a pour fil conducteur la plante, exploitée ou cultivée, les techniques mises en œuvre pour sa culture et son utilisation. Onze articles constituent cet

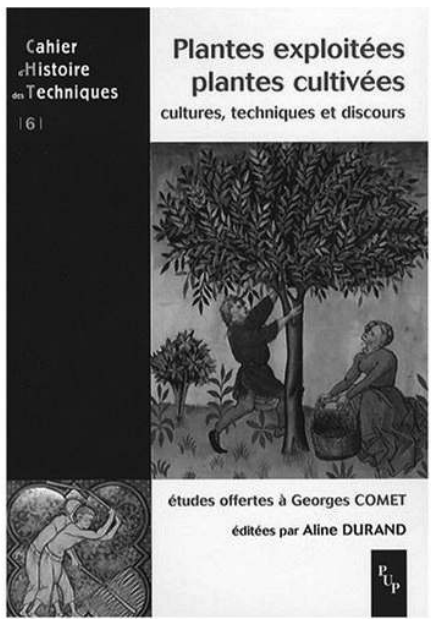
ouvrage, sept axés sur une plante spécifique, quatre traitant plus largement d'un problème agronomique. Deux de ces articles concernent la période moderne ou contemporaine mais la grande majorité traite du Moyen Âge, hommage oblige à un médiéviste spécialiste des techniques agricoles.

2 En introduction, Aline Durand retrace l'itinéraire scientifique de Georges Comet, son intérêt pour l'étude des céréales, de l'outillage agricole, des machines transformant les productions agraires, moulin et pressoir particulièrement. Elle évoque son grand intérêt pour l'olivier comme pour la vigne et le vin, son attachement à l'étude de l'image pour approcher la culture matérielle de la civilisation médiévale, son immersion approfondie dans la littérature agronomique et encyclopédique « qui tissent ainsi, sans jamais le rompre, le lien organique entre technique et société ». Elle parle aussi de son souci d'" enseignant attentif à diffuser les savoirs et les savoir-faire de toutes les manières et sur tous les types de supports ", des livres de synthèse et des manuels aux dossiers photographiques, des films aux présentations muséographiques. Cette évocation est heureusement suivie par la longue et exhaustive « Bibliographie des travaux de Georges Comet », une mine et un précieux instrument de travail.

3 Parmi les plantes évoquées dans cet ouvrage, l'olivier est la plus présente, Provence oblige. Deux articles lui sont consacrés. L'un traite des « Statuts pour l'olivier au Moyen Age » sous le regard des agronomes (Aline Durand). Sont convoqués d'abord les agronomes romains, Caton, Columelle, Palladius, Varon... dont est présentée la conception de la culture de l'olivier. «Cet arbre n'a pas un seul et unique statut : il est à la fois cultivé normalement au sein de l'ager et en même temps sauvage et/ou ensauvagé, mais participant toujours à la construction de l'agrosystème antique ». Ce qui est au centre de la réflexion, ce sont les rapports entre l'olivier cultivé et l'oléastre, l'olivier sauvage, et la place de la greffe. Seuls Columelle et Palladius recommandent la greffe cultivé sur sauvage pour améliorer la productivité de l'olivier. En est-il de même au Moyen Age ? C'est dans la littérature agronomique médiévale italienne que l'auteur cherche la réponse en évoquant le Liber ruralium commodorum de Pierre de Crescent autant que la Divina villa de Corniolo della Cornia. Ces deux agronomes italiens distinguent bien aussi l'olivier cultivé de l'olivier sauvage et pratiquent comme les auteurs antiques autant les greffes, cultivé sur cultivé, que cultivé sur sauvage. Comme dans la tradition romaine, ils font de l'oléastre, l'olivier sauvage, «un élément indispensable à la culture médiévale de l'olivier». L'autre article, "Renouveau de 
l'oléiculture provençale» (Philippe Moustier), nous ramène à l'époque contemporaine. Après avoir connu la prospérité aux XVIII et $\mathrm{XIX}^{\mathrm{e}}$ siècles, l'oléiculture provençale connaît un déclin qu'accentuent, au XX $\mathrm{XX}^{\mathrm{e}}$ siècle, des gels destructeurs. Le regain récent d'intérêt pour l'oléiculture en Provence bénéficie depuis une quinzaine d'années de l'image très positive qu'a conquise l'huile d'olive par ses vertus diététiques. Ce regain d'intérêt pour l'olivier se traduit par la réhabilitation de vergers abandonnés comme par la plantation de nouveaux vergers avec l'aide de la Région, de l'État et de l'Europe. Le verger provençal est le premier bassin oléicole français, un verger inégalement réparti où dominent les Bouches-du-Rhône et le Var, un verger orienté vers la production d'huile mais aussi d'olives confites. Cette relance de la production s'est nécessairement engagée dans des démarches de qualité qui seules permettent la viabilité économique. Ainsi se sont mises en place des Appellations d'Origine Contrôlée, A.O.C. d'Aix-en-Provence, de Haute-Provence, de la vallée des Baux-de-Provence. Et l'auteur d'annoncer la création d'une A.O.C. régionale "Huile d'olive de Provence " dans laquelle les trois appellations déjà existantes deviendraient des sous-ensembles, avec, en toile de fond, une réflexion sur les variétés et les techniques culturales.

«Un désir d'or» (Bruno Laurioux) évoque la production et les usages alimentaires du safran au Moyen-Age. "Dans le riche cortège des épices médiévales, le safran occupe une place singulière ». C'est l'une des plus coûteuses et la première dont on ait réussi l'acclimatation en Europe occidentale, «trouvant en Espagne un terrain d'élection tel qu'elle s'exportait jusqu'au Levant». L'auteur détaille le commerce du safran dans l'occident européen médiéval, les lieux d'échange, la fluctuation des cours. Il explique comment le safran est devenu l'épice d'Occident. Originaire d'Asie, cultivée en Asie Mineure dans l'Antiquité, sa culture est confisquée par l'Europe occidentale, Espagne, Italie, France, d'où il est exporté vers l'Orient. Les auteurs de l'Antiquité classique parlent surtout du safran comme d'un parfum ou d'un médicament. Il n'est présent dans la cuisine qu'à la fin de l'Antiquité. Au Moyen-Age le safran devient un ingrédient obligé de toutes les cuisines surtout en Angleterre et en Italie. Utilisé pour son goût, il l'est aussi beaucoup pour sa couleur. La manière différenciée et subtile dont, à travers l'Europe du Moyen Age, cuisiniers et mangeurs usaient du safran, précise l'auteur, demande encore quelques recherches.

5 "La production et la transformation du chanvre dans la Bourgogne rurale au XIV siècle » (Françoise Piponnier) sont présentées à travers les apports de l'archéologie et des inventaires mobiliers. Les archives permettent de repérer dans les inventaires après décès la présence de chanvre et de graines de chènevis. Les documents qui mentionnent les " héritages " immobiliers permettent de repérer les chènevières. Les fouilles du village déserté de Dracy ont livré des égrugeoirs qui attestent du travail du chanvre, de la récupération de ses graines. Ce site a aussi livré des dents de peignes servant au peignage des fibres. Mais l'archéologie n'a pas permis de reconstituer la chaîne opératoire du travail du chanvre. Nulle trace du rouissage par exemple alors que l'on retrouve dans d'autres fouilles des broies pour le teillage. Les inventaires mobiliers gardent traces $d u$ travail $d u$ fil et $d u$ tissage, de la présence de toiles. Autoconsommation et vente de ces toiles par les villageois bourguignons du XIV ${ }^{\mathrm{e}}$ siècle peuvent-être supposées.

6 «L'exploitation de la feuille d'arbousier dans le massif des Maures à l'époque moderne » (Bernard Romagnan) permet la mise sur le marché d'un matériel végétal riche en tanin, produit indispensable pour la transformation des peaux en cuir. La forte 
teneur en tanin de ces feuilles en fait un produit recherché. L'essartage sur les pentes des Maures crée un espace agricole et forestier favorable à l'exploitation de la feuille d'arbousier. On y fait deux récoltes, au printemps et en été. Descendues sur le rivage par le fournisseur, ces récoltes sont alors prises en charge par des négociants. Les archives ont livré de nombreux contrats de vente qui permettent de mieux cerner les acteurs de cette exploitation. Mais ce sujet n'a été qu'effleuré. «Un champ nouveau d'investigation s'ouvre, dans lequel devront être expliquées les étapes de la chaîne opératoire qui va de la cueillette de la feuille d'arbousier à son utilisation dans la tannerie ».

7 «La parole des grains » (Marie-Pierre Ruas) présente une enquête archéobotanique sur l'engrain (Triticum monococcum L.) au Moyen Age en France méridionale, menée grâce aux possibilités de la carpologie. Après une présentation du patrimoine céréalier méridional, l'auteur insiste à juste titre sur le rapport des mots et des grains, cartographiant les différentes appellations de blé vêtu relevées dans les archives. Le report sur cette même carte des données de 57 sites archéologiques médiévaux où l'on a trouvé ce blé vêtu éclaire fortement les liens entre ces mots et ces choses. Cette carte est accompagnée de tableaux présentant les mentions du blé vêtu dans des textes médiévaux et modernes et les références des sites avec analyse carpologique, reportées sur la carte. L'auteur poursuit en évoquant le rapport entre le grain cultivé et ses adventices, mélange voulu ou mélange subi, relation entre l'engrain et d'autres céréales. Puis il évoque des hypothèses sur le maintien et le rôle de l'engrain depuis l'époque médiévale. Son propos permet de cerner les facteurs qui ont pu « régir le maintien ou la disparition de l'engrain dans les agrosystèmes médiévaux ». Une riche bibliographie vient étayer ce propos.

8 «Quelques mots sur le tournesol " (François Sigaut) nous ramènent au XIX ${ }^{e}$ siècle. L'auteur souligne d'emblée qu' « un aspect mal étudié de l'histoire de l'agriculture au $\mathrm{XIX}^{\mathrm{e}}$ siècle est le développement des plantes industrielles ", développement qui fut explosif. Alerté par les écrits de Victor-Frédéric-Alexandre Ysabeau (1793-1873), il nous propose de se pencher sur le tournesol, non pas le tournesol oléagineux mais le tournesol tinctorial, plante spontanée longtemps plante de cueillette, mise en culture seulement au XIX ${ }^{\text {e }}$ siècle et qu'on trouve dans le Midi sous le nom de morelle ou maurelle. "On tirait de la maurelle un jus dont on imbibait des toiles, appelées drapeaux, qui étaient soumises à l'action de vapeurs d'ammoniaque ». Ces drapeaux ainsi traités étaient expédiés aux Pays-Bas où on en tirait une teinture connue dans le commerce sous le nom de «bleu de Hollande ». Ce qui intéresse l'auteur de l'article ce sont les traces qu'a laissées cette maurelle dans la littérature agronomique, de l' Encyclopédie Méthodique au Cours d'Agriculture du comte A. de Gasparin et au Dictionnaire d'Agriculture, Encyclopédie agricole complète de J.-A. Barral et $\mathrm{H}$. Sagnier, et comment sa démarche de redécouverte de la maurelle peut éclairer de nouvelle recherche sur des plantes industrielles et des techniques oubliées des historiens.

9 La suite des articles de ce volume nous ouvre sur une réflexion agronomique plus large. «De l'influence de la lune» (Philippe Bernardi) conduit à une interrogation sur l'abattage des arbres à la fin du Moyen Age. La lune peut-elle exercer une influence plus ou moins favorable sur la qualité des bois? A travers des sources d'archives provençales et des écrits techniques comme le De re aedificatoria de Leon Battiste Alberti ou les Nouvelles inventions pour bien bastir de Philibert De L'Orme, il cherche à cerner ce qu'est le «bois de bonne lune». Croyance populaire ou préoccupation savante, de 
quelle nature serait l'influence de la lune? Et quelle est la bonne lune? Lune jeune, lune vieille? "Si les sources réunies montrent que les Provençaux accordaient indubitablement de l'importance à la lunaison lors de l'abattage des arbres, il nous faut bien constater que, dans le détail, leur croyance en la matière se laisse difficilement appréhender » souligne l'auteur. Cette étude sur l'influence de la lune sur les bois n'est qu'un exemple d'une problématique plus vaste, celle de la croyance en l'influence de la lune en agriculture. "Rejoignant les domaines de l'astrologie et de l'astronomie, l'histoire des techniques souligne la cohérence d'une société où la détermination de la période la plus favorable à l'abattage d'un arbre n'est pas sans parenté avec les calculs savants destinés, par exemple, à déterminer la date d'une fête aussi importante que celle de Pâques » conclut l'auteur.

10 «Les jardins de Rome aux XIII e et XIV ${ }^{e}$ siècles » (Alfio Cortonesi) s'ouvrent alors à nous. Si les grands domaines, la céréaliculture, l'élevage et la viticulture ont été bien étudiés par les historiens de la Rome de la fin du Moyen Age, il n'en est pas de même de l'horticulture. La raison en est sans doute une documentation maigre et fragmentaire tirée des archives ecclésiastiques et des actes notariaux. " Au même titre que la vigne, comme culture charnière entre espace urbain et campagne, le jardin réalise son expansion maximale sur les surfaces les moins denses hors de l'habitat ». Les archives montrent qu'artisans et cultivateurs, petits propriétaires et locataires de biens ecclésiastiques se consacrent chaque jour au soin d'une ou plusieurs pièces de terre. Il faut ajouter à cela les nombreux jardins des monastères et des chapitres. Les vignes et les jardins se partagent souvent les mêmes terrains. Les données sont très fragmentaires pour cerner les cultures pratiquées. Pour la fin du XIII ${ }^{\mathrm{e}}$ siècle, la liste des dépenses de la Domus Helemosinae Sancti Petri donne des indications détaillées. On note des achats de légumes presque tous les jours. Choux, laitues, pourpiers sont fréquents ainsi que courges et oignons alors que les racines, raves et carottes, sont rares contrairement aux poireaux, à l'ail et aux herbes aromatiques. Par contre les sources ne permettent pas de bien cerner la place des légumineuses et des arbres fruitiers. Cependant la présence de bigaradiers (oranges amères) est attestée. Un parallèle aurait été souhaitable entre ces cultures et la cuisine de l'époque à Rome. L'évocation de la propriété et de la location des jardins clôt cet article très descriptif.

11 "L'amendement des sols en France du Nord aux XII ${ }^{e}$ et XIII ${ }^{e}$ siècles " (Robert Fossier) nous ramène à des problèmes techniques. L'auteur distingue bien les «façons » et les « amendements » de la terre dont on veut tirer tout le profit. Dès le début de son travail sur «L'histoire technique des céréales", Georges Comet avait écarté cette recherche sur les amendements qui l'aurait entraîné trop loin de son sujet. C'est cette recherche que se propose de faire l'auteur de cet article à partir de sources limitées, une soixantaine d'allusions en Picardie entre 1100 et 1300 . Il note qu'il faudra attendre le début du XII ${ }^{e}$ siècle pour que la fumure liée aux déchets des animaux quitte le jardin pour le champ. Nature et volume des litières sont alors capitales. Parallèlement la "colombine ", déjections de pigeons, de colombes, fumure très riche, est recherchée par les puissants pour leurs jardins. L'obligation de fumures sur les terres données à bail, les problèmes techniques de l'épandage sont aussi abordés. Autre type d'amendement, le marnage des sols argileux et le chaulage, avec les mêmes obligations dans les baux. Dernier mode d'amendement qui n'a pas l'importance des précédents, le tourbage des sols trop mous et trop argileux. "Le résultat global de l'emploi d'engrais naturels, animaux ou minéraux, est, évidemment, un gain certain de productivité, trait bien connu de l'évolution agricole médiévale ». Cette étude apporte des confirmations : 
«la place de l'élevage et les formes qu'on lui a données constituent un élément primordial de l'économie vivrière médiévale: sans fumure pas de gras épis, pas de triomphe des blés en ces régions " mais aussi importance des pratiques usagères que le marnage et le tourbage rendaient indispensables, dans le renforcement des communautés paysannes.

12 «L'essartage dans les Alpes occidentales au prisme des sources écrites du Bas Moyen Age » (Fabrice Mouthon) clôt cette série d'articles. Ces essarts sont des abattis-brûlis servant de base à des cultures temporaires, l'essartage étant à voir comme une méthode de préparation de la terre. Du Valais à la Méditerranée, le droit d'essartage apparaît comme très réglementé ce qui le rend présent dans de nombreuses sources d'archives : censiers, sources judiciaires, "révisions des feux », chartes de franchises... L'auteur s'interroge sur l'essartage comme pratique de misère, sur son lien avec les communaux, avec le saltus. Il aborde d'abord l'essartage comme une pratique agronomique qui a ses méthodes. Il analyse les rapports du bois et de sa cendre avec le grain et l'herbe. L'essartage est ensuite vu comme source de problèmes juridiques et d'enjeux économiques, lieux de confrontation entre les droits du seigneur et les besoins et droit de la communauté rurale, entre le désir qu'a le seigneur de protéger la forêt et la recherche de sols riches. L'essartage est aussi abordé dans son rapport à la conjoncture démographique, abandon ou reprise des défrichements temporaires par le biais de cette technique du feu selon les fluctuations de la population. "Dans les sources du Bas Moyen Age, l'essartage apparaît surtout pour être remis en question, admis avec réserve, au mieux réglementé, au pire interdit...La raison principale n'est sans doute pas la déforestation en tant que telle... Le problème réside sans doute dans le fait que l'essartage, comme les autres droits d'usage coutumiers, entre en concurrence avec d'autres formes d'exploitations des bois plus rémunératrices » conclut l'auteur de cette contribution.

On aura compris par le compte-rendu fait de ces différents articles que cette publication est d'une grande richesse et ouvre sur de nombreuses pistes de recherche à l'image de l'œuvre de Georges Comet à laquelle elle veut rendre hommage. Le Cahier d'Histoire des Techniques numéro 7, deuxième recueil d'études offertes à Georges Comet à paraître sous le titre "Jeux d'eau. Moulins, meuniers et machines hydrauliques, $\mathrm{XI}^{\mathrm{e}}-\mathrm{XX}^{\mathrm{e}}$ siècles » devrait confirmer la valeur de cette démarche. 